\title{
Temario para la discusión de un proyecto social alternativo
}

Pedro Vuskovic Eduardo Ruiz CIIH-UNAM

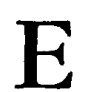

n diversos países latinoamericanos se han venido difundiendo crecientes preocupaciones en torno al diseño, la viabilidad y las formas de poner en práctica un proyecto social alternativo a las tendencias predominantes. Con sus peculiaridades correspondientes, tales preocupaciones están presentes tanto en los medios académicos como en las organizaciones políticas y sociales y en la propia base de la sociedad. La comunicación entre tales empeños ha sido sin embargo escasa y no se han dado oportunidades propicias para avanzar colectivamente en las respuestas al desafio que todo ello entraña.

La reunión de trabajo a la que se destinan estas notas busca precisa- mente ese propósito, a partir de un documento de referencia como éste, encaminado a levantar más preguntas que a sugerir respuestas, de modo que estimulen un diálogo enriquecedor indispensable.

\section{LAS RAZONES DEL NEOLIBERAIISMO}

El tema pudiera parecer secundario ante una realidad inmediata en la que se han impuesto, con un respaldo sorprendentemente amplio, las concepciones - no sólo económicas, sino también sociales y políticas- que de modo general se asocian al "neoliberalismo". Se atribuye a sus formula- 
ciones la condición de constituir una respuesta idónea a la profunda crisis que afectó a las economías latinoamericanas desde 1980, un camino congruente con los grandes cambios que están teniendo lugar en la economía y el sistema mundiales, la única alternativa viable después de los fracasos de los "socialismos reales" de la Unión Soviética y Europa del Este, y una rectificación indispensable después de las experiencias "estatistas" y "populistas" en la América Latina. Las propias políticas "de ajuste" que se pusieron en práctica para conjurar la crisis, si bien no lograron sus propósitos inmediatos, prepararon el terreno para la aplicación de un nuevo "modelo", supuestamente capaz de hacerse cargo no sólo de las herencias objetivas del desarrollo anterior sino también de sus proyecciones teóricas e ideológicas.

Respalda además la difusión de esas imágenes una constelación de fuerzas representativas de poderosos intereses de dentro y de fuera, que resultan directamente beneficiadas por las políticas correspondientes. Invocando en su favor interpretaciones sesgadas de la historia, encuentran terreno abonado para la crítica fácil al estatismo, al populismo, a la autarquía, al proteccionismo, a la autonomía nacional y a la equidad social. De otra parte, invoca en su favor las supuestas cualidades del "realismo", la valoración del pragmatismo por sobre la "utopía"; se proclama portadora de una promesa de libertad económica como base de libertad política, y defiende el imperio del mercado como el instrumento único de asignación eficaz de recursos. Se autoatribuye la condición ex- clusiva de portador de la "modernidad", del progreso técnico, de la eficiencia. Por esas aparentes cualidades, esas fuerzas se atribuyen la condición de únicos agentes auténticamente democráticos, despreciando la historia y el papel político del pueblo.

Con toda esa fuerza de respaldo, objetiva, y subjetiva, define una estrategia económica que constituye a las exportaciones en el factor principal de dinamismo del crecimiento, preconiza consecuentemente la más incondicional apertura externa y busca sostener los términos más favorables posibles de competitividad en los mercados mundiales; reduce drásticamente el ámbito de acción del Estado y propicia la privatización de toda suerte de actividades productivas y servicios; se apoya fuertemente en la contribución financiera externa y ofrece las mayores franquicias y estímulos al capital extranjero; en la conducción de la política económica de corto plazo, jerarquiza por sobre cualquier otro objetivo el mantenimiento de los "equilibrios macroeconómicos" según se expresan en las cuentas fiscales y externas $y$ en las presiones inflacionarias, y entrega a las "fuerzas del mercado" la responsabilidad de la asignación de los recursos. Además, desprecia la búsqueda de una integración latinoamericana independiente y sólo se concibe una articulación apendicular con los polos mundiales de mayor desarrollo. Para facilitar esta estrategia económica se permite la depredación y agotamiento de los recursos naturales y el deterioro por contaminación de los espacios vitales de nuestros países. 
La concepción desborda, en rigor, las dimensiones económicas, proyectándose decisivamente en el conjunto de la vida social. La interrelación entre los dos planos es obvia, en cualquier circunstancia, pero se acentúa al extremo bajo las imposiciones del neoliberalismo. En efecto, éste define mucho más que una estrategia económica y una forma específica de conducir los procesos económicos: involucra consecuencias nacionales y muy profundas y conlleva valores morales y conductas individuales y colectivas que se promueven y justifican al amparo de esa concepción económica; distorsiona gravemente incluso los criterios de evaluación de los resultados económicos: según la idea predominante, la economía puede ir bien aun- que liz esté yendo mal a la mayoría de la población; o importan más los equilibrios macroeconómicos que la condición esencial de vida de todos.

Las transformaciones económicas se acompañan, a su vez, de transformaciones no menos significativas en las formas de manejar las relaciones políticas. El proyecto neoliberal pone en marcha, en efecto, una suerte de segunda fase de cambios que busca dar continuidad a los procesos de "derechización" mediante la búsqueda de nuevos patrones de desarrollo y administración del capitalismo como sistema.

Es así como, en el plano político, se produce una concentración de poder, correlativa con la concentración económica, ubicándose la capacidad

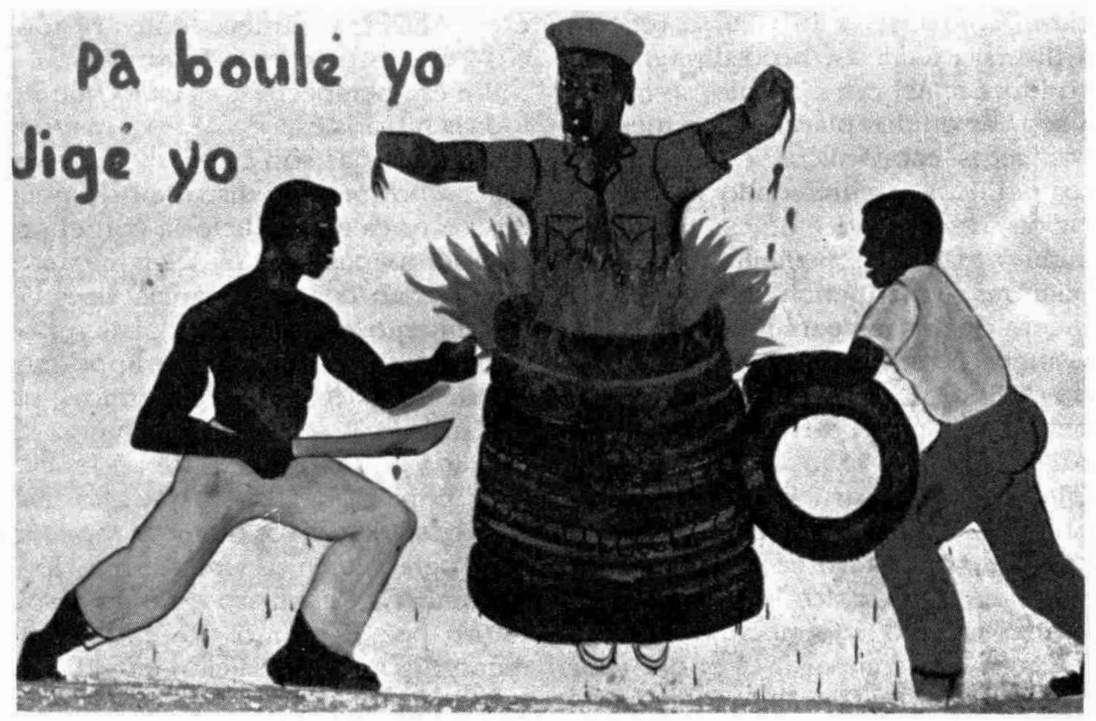

UN PROYECTO SOCIAL ALTERNATIVO 
de decisiones políticas en una elite que sobrevalora lo formal-democrático, reconociéndolo satisfecho en la realización de elecciones periódicas independientemente de la calificación que corresponda hacer del sistema electoral y de los grados de participación en esos procesos. Los municipios y los parlamentos tienden a constituirse en marcos de mediaciones más aparentes que reales, y los sistemas electorales se mantienen extremadamente restrictivos y soslayan la proporcionalidad como base para la proclamación de los electos.

Los mismos efectos económica y socialmente desintegradores del neoliberalismo realzan la necesidad de procurar mecanismos de atenuación de los conflictos, hasta el punto de destacar el concepto de "gobernabilidad" como una de las cuestiones políticas clave, con vistas a lo cual se recurre a diversas técnicas, procedimientos y conductas. Así por ejemplo, se tiende a separar en dos planos diferentes los conflictos económicos y los conflictos políticos, oscureciendo su interrelación, reservándose de ese modo un ámbito mayor de flexibilidad política mientras se mantienen extraordinariamente rígidos los parámetros y las decisiones económicas. Las luchas por las reivindicaciones sociales tienden a perder su carácter de movilización global y nacional, reduciendo sus posibilidades a la participación en conjunto de la sociedad. Es también la condición para favorecer términos de alianza política entre la derecha y el centro, incluso bajo modalidades que les permitan compartir el poder (por ejemplo: incorporando la fórmula de un presidente y un primer ministro), y compartiendo el propósito de mar. ginar a la izquierda. Se trata, en suma, de una suerte de "neooligarquización". democrática, con más apariencia consensual pero a la vez con un claro sentido de exclusión. La democracia pierde su sentido "participativo" y se privilegian los mecanismos de "control político" para impedir alternativas de poder no controladas.

Son las expresiones políticas del neoliberalismo, que acompañan y se corresponden con sus manifestaciones económicas. En todo caso, es preciso reconocer que son sus dimensiones económicas las que están sobredeterminando sus rasgos sociales y políticos, y que es por lo tanto en el terreno económico donde se decide su suerte. Interesa, por lo mismo, profundizar en su significado económico esencial, en sus antecedentes históri$\cos$ y en sus promesas de futuro.

En esa perspectiva, es claro que no toda la historia está de su lado, ni todas sus propuestas son enteramente nuevas. Su promesa de distribuir después de crecer es contradictoria con el hecho de que las sociedades latinoamericanas han conocido largas fases de crecimiento económico global relativamente rápido y cambios importantes en sus estructuras económicas, en la distribución sectorial de la fuerza de trabajo y la composición urbano-social de la población, a la vez que alcanzan niveles significativos de incorporación de progreso técnico y modernización. Sin embargo, esos procesos no resolvieron por sí mismos los problemas esenciales de la condición de vida del conjunto de la población; por el con- 
trario, los indicadores que dan cuenta de la situación social se han mantenido en niveles muy insuficientes y en algunos casos se han deteriorado en el curso de ese desenvolvimiento, en el que tampoco se logró afirmar una dinámica propia de crecimiento, a lo que se agregan previsiones respecto del futuro próximo que por lo demás no parecen ofrecer perspectivas de crecimiento de intensidad siquiera comparables a las del pasado.

El designio exportador no es una propuesta nueva, ni lo es tampoco la esperanza de que los consumos de las capas de alto ingreso, alentados por la modernización, se constituyan en factor de impulso dinámico al conjunto de la economía nacional. De hecho, con distintos grados de acento en uno y otro, han esperado siempre el dinamismo desde dos fuentes complementarias: la demanda externa -las exportaciones-y las demandas internas de los grupos minoritarios que han concentrado altas cuotas del ingreso nacional, y han enfrentado el agotamiento progresivo de la función dinámica de una y otra. De las exportaciones, porque las condiciones de la economía mundial han llevado a una pérdida persistente de la participación relativa de América Latina en un comercio mundial que se concentraba cada vez más en el intercambio entre los propios países capitalistas desarrollados; y de la demanda interna de alto ingreso, porque la desigualdad pudo constituirse transitoriamente en aliento a los esfuerzos industrializadores, pero ha terminado por constituirse en un freno a la continuidad del crecimiento.
Esa perspectiva da cuenta, en última instancia, de la incapacidad del subdesarrollo latinoamericano para abrir, en los marcos del capitalismo dependiente, una dinámica duradera de progreso y desarrollo. El neoliberalismo viene a representar así la búsqueda última de defensa y prolongación del sistema, la forma de dar continuidad a un desarrollo capitalista que ha desembocado en situaciones de abierta crisis. El desafio del cambio aparece ahora no sólo ante quienes buscan redefinir la orientación del crecimiento económico en función de intereses sociales distintos de los actualmente dominantes, sino también a quienes buscan proteger y defender la posición de esos intereses, sin perjuicio de que procuren justificar sus propuestas invocando razones de orden más general: por ejemplo, argumentando que la economía mundial se reestructura en torno a unos pocos grandes bloques económicos supranacionales y que es insoslayable la adscripción plena a uno de ellos si no se quiere quedar condenado a la marginación y al atraso; o reiterando la idea de que el crecimiento global, y no la distribución, es la única fuente potencial del mejoramiento generalizado de la condición de vida, y asegurando que para uno y otro propósito son indispensables las condiciones de estabilidad económica, lo que a su vez exige que 'se coloque en el primer orden de prioridades a los "equilibrios ma. croeconómicos". En esta perspectiva, se elimina toda consideración a una acentuación de la relación de dependencia y a la facilidad que se concede a los designios imperiales en nuestros 
países. Menos se admite la condición crítica que vive la economía mundial, que se sintetiza en la condición deficitaria y recesiva de la economía norteamericana.

Al colocar las expectativas reactivadoras y de desarrollo futuro en el dinamismo exportador, se tiene que emprender una "reconversión" profunda del sistema productivo; un esfuerzo de "modernización" que coloque al sector de los bienes "transables" lo más próximo posible a los de las economías desarrolladas en términos de organización, tecnificación y eficiencia; libertad, con el mínimo de trabas, de comercio exterior y de flujos financieros externos, así como de los precios internos, con la sola excepción de la remuneración del trabajo que sigue bajo control como elemento clave de la competitividad y la estabilidad financiera del sistema; todo lo cual requiere, a su vez, la más amplia vigencia del mercado como el mecanismo fundamental de asignación de recursos, lo cual significa privatización de toda suerte de actividades de provisión de bienes y de servicios, así como el máximo de "neutralidad" de la política económica oficial. Objetivos no alcanzables sino mediante una altísima concentración de esfuerzos y recursos; es decir, la aplicación de todo lo movilizable en una parte de la economía y con vistas a que sirvan a una parte de la sociedad. Involucra así una especie de reconocimiento implícito de que a partir de la crisis y el conjunto de las circunstancias actuales no habria posibilidad de soluciones de escala verdaderamente nacional, en el sentido de que pudieran alcanzar al conjunto de la economía y a toda la sociedad, poniendo de manifiesto, en su esencia, consecuencias inexorables de "segregación" interna.

Es decir, lo que está predominando en la práctica es una estrategia de fuerte articulación externa, bajo dominio del capital transnacional, y de desintegración social interna, que conduce a una sociedad escindida, un "mundo de los ricos" y un "mundo de los pobres" increíblemente diferenciados y vinculados sólo por relaciones de extrema explotación. Se configura un segmento moderno, de alta productividad y eficiencia, que produce para la exportación y los consumos suntuarios, a la vez que se mantiene un estrato rezagado de muchos productores y vendedores pobres que producen y venden los productos básicos para unos consumidores cada vez más pobres. Razón, también, por la que las situaciones de pobreza, que es insoslayable reconocer en sus dimensiones y en su aumento continuo, no pueden comprenderse si no se las vincula con la desigualdad.

Lo paradójico es que, no obstante tales constataciones, la ideología neoliberal ha sido capaz de difundir e imponer un conjunto de "ideas-fuerza" que la sustentan; incluida entre ellas la aseveración de que no habría en las condiciones actuales otra posibilidad, otras opciones, y que tales propuestas constituirian una exigencia ineludible de este presente.

\section{LA RESPONSABILIDAD SOCIAL DE} UNA ALTERNATIVA

Bastarían aquellas consecuencias de segregación social, apenas amortigua- 
das por la promesa de restituciones futuras, para legitimar la necesidad de una propuesta social alternativa. Hay todavía más, sin embargo.

El hecho es que tras varios años ya de aplicación, extendiéndose de unos países a otros hasta comprender a la mayor parte de América Latina, las políticas neoliberales no muestran objetivamente un balance positivo. Es verdad que han contribuido a reactivar las exportaciones, pero su mayor efecto ha sido mejorar la balanza comercial externa de modo que se pueda financiar el volumen impresionante de pagos al exterior por concepto de servicio de la deuda acumulada, remesas de ganancias y otras restituciones y salidas de capital. Han favorecido el restablecimiento de equilibrio en las cuentas fiscales, pero lo han hecho al precio de contraer drásticamente la capacidad de acción pública, privatizar y encarecer servicios básicos, y condenar al desempleo a importantes contingentes de funcionarios públicos. Han disminuido la intensidad de la inflación, al costo de contraer la capacidad de compra de la mayoría de la población. Por su parte, los deterioros sociales han sido graves, y aun así la recuperación del crecimiento económico ha sido mínima. Según los datos de la CEPAL, el producto interno bruto registró un aumento de apenas $0.3 \%$ en 1990 y un [modesto] 2.4\% en 1991, acabando por acumular una disminución del producto por habitante de $8.8 \%$ entre 1981 y 1991; reconoce que las contradicciones entre "incorporación y exclusión, integración, y desarticulación, modernización y heterogeneidad, ten- dieron a reproducirse casi como condición de funcionamiento de la moda. lidad de desarrollo".

La eficacia de las políticas económicas y sociales del neoliberalismo como vía para reabrir una dinámica de desarrollo es pues, hasta el presente, sólo una promesa, no avalada por los datos de la realidad. Pero entretanto, los sacrificios sociales son un hecho inmediato inocultable. Y de manera más general, es preciso tener conciencia del grado en que las concepciones económicas predominantes están determinando -y seguirán condicionando- el conjunto de la vida social en sus más diversas manifestaciones. Constatación que estaría lla. mada a constituirse en un signo de alarma respecto de cómo evolucionarían nuestras sociedades si se prolongara mucho más la aplicación de las políticas económicas actualmente en práctica.

Se podrá decir que la interrelación entre los dos planos de la vida social es obvia en cualquier circunstancia; pero hay también que reconocer que se acentúa al extremo bajo las imposiciones del neoliberalismo. En efecto, como se dijo, éste define mucho más que una estrategia económica y una forma específica de conducir los procesos económicos; involucra consecuencias nacionales muy profundas, y conlleva valores morales y conductas individuales y colectivas que se promueven y justifican al amparo de esa concepción económica. Se explica así que, en algunos casos, poco más de tres lustros de aplicación de tales políticas hayan sido suficientes para que el individualismo y la competitivi- 


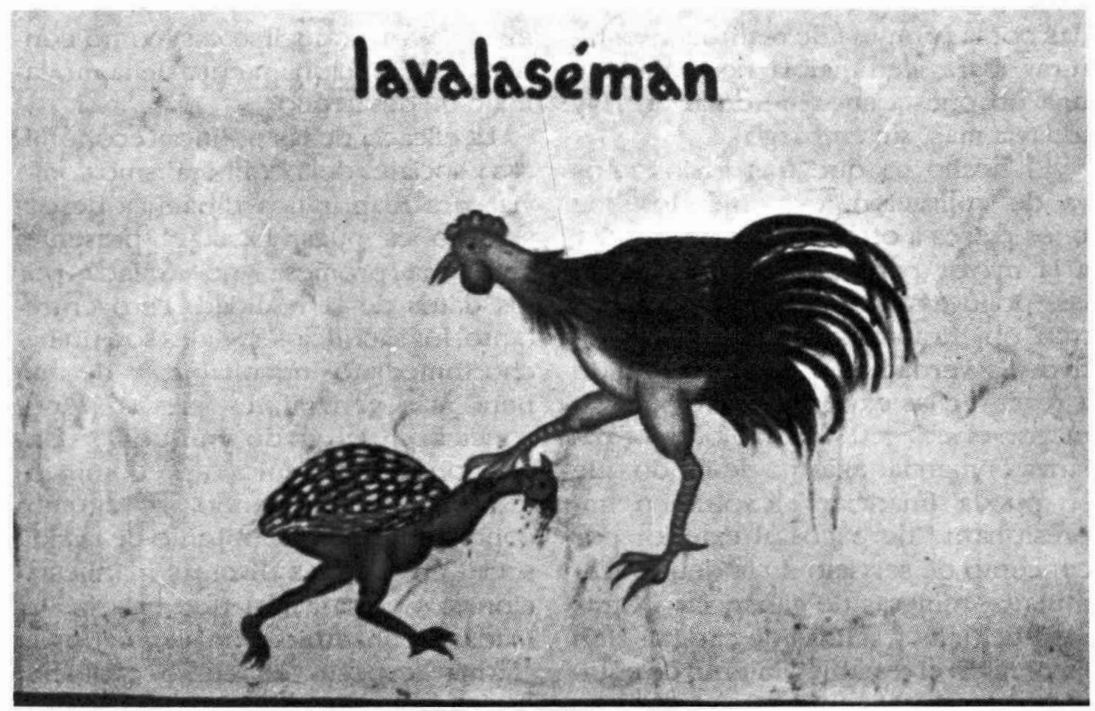

dad se impongan en las conductas de buena parte de la población, por sobre los valores de la solidaridad y el compromiso social.

Los riesgos son ciertamente muy grandes. En tales condiciones, el afianzamiento y el desarrollo de la democracia no quedan para nada garantizados; por el contrario, los extremos de desigualdad y diferenciación social, la . escisión abierta de las sociedades, acaban por requerir del autoritarismo civil o militar y de la represión política capaces de imponerlos y sostenerlos. La apertura y la expansión continua cada vez más difícil, de nuevos mercados externos, lleva a esquemas de integración incondicional a las economías de la región más desarrolladas, con el sacrificio consiguiente de auto- nomía nacional y de los propios beneficios derivados de esa integración. La función clave que se atribuye a las exportaciones tiende a prolongar los niveles deprimidos de los salarios internos como base de competitividad exterior, así como a incurrir en explotaciones cada vez más depredatorias de los recursos naturales. El mercado, en su imperio absoluto, genera y profundiza las desigualdades, concentra propiedad e ingreso, acentúa las heterogeneidades estructurales.

Frente a ese cuadro de prevenciones, que no carece de fundamento, el empeño sistemático por diseñar un proyecto social alternativo, abrirle vialidad y procurar que se conforme la correlación de fuerzas sociales capaces de impulsario y sustentarlo, pasa 
a ser una responsabilidad ineludible para quienes se sitúan del lado de los intereses nacionales y populares.

\section{LA NECESIDAD DE UN NUEVO PROYECTO ALTERNATIVO EN UN MARCO NEGATIVO}

Acoger consecuentemente esa responsabilidad constituye hoy día una tarea singularmente ardua y compleja.

A diferencia de otras coyunturas históricas que demandaron cambios en las estrategias de desarrollo, no se trata esta vez de encaminar nuevas propuestas que busquen modificar parcialmente las estrategias en práctica, para incorporar en ellas propósitos adicionales o adecuarlas a otras preferencias sociales. El neoliberalismo constituye una concepción y un proyecto global, generador en su fun. cionamiento, de una dinámica propia que entrelaza sus diversas dimensiones en interacciones $e$ influencias recíprocas que se refuerzan mutuamente de modo bastante implacable. Si bien subsisten propuestas "intermedias", como la simbolizada en la expresión "crecimiento con equidad" (el "capitalismo humanizado" según la expresión popular), en la práctica resultan inviables, porque las dinámicas del sistema son tan rígidas que no dan lugar a concesiones significativas. Un proyecto alternativo tiene por lo tanto que asumir el carácter de una opción también global, en sus dimensiones económicas, sociales y políticas, lo cual involucra revertir la mayor parte de las tendencias y direcciones en que camina la propuesta neoliberal. Por lo mismo, los "agentes" capa- ces de hacerse cargo del nuevo proyecto son también otros, que tienen que abrirse paso èn oposición abierta a los actuales actores del poder.

Acaso sea sugerente cotejar una situación como ésta con antecedente de la propia experiencia de América Latina, como aquella que marcó el cambio del patrón de "crecimiento hacia afuera" al de "crecimiento hacia adentro" o "industrialización sustitutiva", porque entonces la sustitución de importaciones venía teniendo lugar en la realidad y sus promotores ac. cedían a una cuota importante del poder político, de manera que la nueva estrategia podía abrirse paso apoyada en fuerzas ya en pleno desarrollo y comandada por agentes que ya disputaban posiciones de poder desde el interior del sistema. Ahora, en cambio, se trata de revertir mucho de lo que está en curso y construir desde fuera del poder una fuerza social capaz de disputarlo frente a la resistencia tenaz de quienes disfrutan de la situación actual y sus tendencias.

Una segunda gran dificultad tiene que ver con el hecho de que el neoliberalismo está llevando con toda crudeza la identificación de las opciones sociales a los grados más extremos de decisión respecto de las formas de vida a que aspira y respecto de qué fracciones de la población pueden acceder a ellas. La aritmética de la desigualdad se hace entonces evidente en sus términos más brutales, porque la apertura externa involucra la asimilación de las formas de vida y consumo de las sociedades más adelantadas, de sus hábitos y preferencias, incluso de sus productos, que 
se hacen accesibles mediante impor: taciones favorecidas por el mercado abierto. Se busca así internalizar pautas de vida características de sociedades cuyo desarrollo global de las fuerzas productivas les permite obtener ingresos que promedian los $10 \mathrm{o}$ 12000 dólares más por persona al año; pero la asimilación de ellas en sociedades en que ese grado de desarrolo alcanza, como son los casos más favorables de América Latina, a cifras del orden de los 2000 dólares anuales por persona, plantea inexorablemente la razón aritmética de la desigualdad: sólo son alcanzables en la medida en que una fracción relativamente pequeña de la población reúne ese ingreso; pero al hacerlo, está contrayendo a niveles muy inferiores los ingresos del resto de la masa social, que así accede apenas a patrones de vida de escasa sobrevivencia.

Este es el punto tal vez más drásticamente crucial de un proyecto alternativo: qué propone respecto de los accesos a los frutos del esfuerzo económico, qué grados de diferenciación social le resultan aceptables, cuáles son las dimensiones mínimas de integración social interna a que se debe aspirar. Teniendo en cuenta que así como hay que reconocer las consecuencias de una "aritmética de la desigualdad" también hay que reconocer las consecuencias de una "aritmética del igualitarismo": a determinado nivel de desarrollo global, mientras más igualitaria sea la distribución de ingreso, mayor es la inaccesibilidad a bienes y servicios no esenciales de que disfrutan sociedades de mayor nivel de desarrollo (como puede muy bien ilus- trarse con referencia a la experiencia de Cuba, descontados desde luego los efectos del bloqueo). La decisión social de este orden es a su vez determinante de la conformación que tiene que asumir la estructura productiva, y se proyecta igualmente en las estrategias políticas de absorción tecnológica y en la función que quedan llamados a cumplir los diferentes "agentes de la producción", con la consideración adicional, singularmente importante, de que el dinamismo sostenido de crecimiento económico del sistema es con toda probabilidad mayor en los marcos de un esquema más igualitario que difunde más sus frutos, que en uno de desigualdad, concentración y segregación social.

Una tercera consideración de este orden tiene todavía que ver con las condiciones de partida para la puesta en práctica de un proyecto alternativo, porque el neoliberalismo ha venido congelando condiciones, situaciones y herencias, $y$ redefiniendo instrumentos que al adecuarlos a su concepción particular se constituyen en obstáculos o carencias muy grandes para otra orientación de la conducción social y económica. Ocurre así, en efecto, en varios planos. La apertura externa ha conducido a grados muy estrechos de articulación con el capital transnacional, mediante inversiones directas y diversas formas de asociación, que actúan con una lógica de situación mundial y no de situaciones o aspiraciones nacionales, y la subordinación se ha acentuado aún más por la dependencia de mercados externos, de tecnologías y suministros de insumos claves, restringiendo severamente 
el ámbito de las decisiones nacionales autónomas. La reconversión productiva, con la prioridad concedida a los bienes "transables", de gran sensibilidad a la actividad exportadora, ha debilitado la capacidad de autosuministro de amplias categorías de bienes. La reducción de las funciones del Estado y la privatización de las mismas estrecha la capacidad de acción social y el control sobre los procesos productivos y sociales. Han cristalizado nuevas formas, muy concentradas, de propiedad, incluso de propiedad de la tierra, muy difíciles de revertir. Las propias disposiciones juridicas se han adecuado a las exigencias del proyecto neoliberal, reduciendo facultades e imponiendo obligaciones que hacen más difícil la materialización de un proyecto social alternativo. Y muchos de los grandes parámetros sociales, conformados durante el curso de la historia, han sido alterados fuertemente: las relaciones de distribución del ingreso y de la propiedad, con participaciones de los salarios en el ingreso nacional, extraordinariamente disminuidas, los derechos individuales y sociales $y$ los ámbitos de la participación popular en las grandes decisiones.

De este modo, un proyecto alternativo en las condiciones contemporáneas está llamado a encontrar muchas mayores dificultades de realización que las que enfrentaron, por ejemplo, las propuestas latinoamericanas de formas de "desarrollo no capitalista" en los años sesenta y setenta, cuando podría contarse con muchos de aquellos elementos de flexibilidad o apoyo. La propia drastici- dad del proyecto neoliberal obliga a configurar una opción que ticne que proponerse la reversión de casi todo lo que ahora estă en marcha: recuperar grados de autonomía nacional y de capacidad de conducción social de los procesos económicos, subordinar los esfuerzos exportadores a la satisfacción de las necesidades básicas internas, detener la concentración de la propiedad y procurar formas de mayor difusión de ella, revertir la desigualdad hacia un reparto más equitativo de los frutos, realzar los valores de la solidaridad y la convivencia sobre los de la competitividad y el individualismo. Por lo mismo, tiene que ser un proyecto mucho más transformador, lo que a su vez supone, como condición de viabilidad, el respaldo activo de una amplia mayoría social: un requisito político favorecido por la medida en que las concepciones neoliberales afectan adversamente a la mayoría de la población, pero con las mayores resistencias subjetivas derivadas de la eficacia de la campaña ideológica neoliberal y el extendido escepticismo respecto de la capacidad de otros agentes sociales para conducir una opción viable y trascendente.

Como quiera que sea, la fucrza potencial de un proyecto alternativo está llamada a acrecentarse directamente por las consecuencias de largo plazo de la estrategia neoliberal, la constatación cada vez más ostensible de su incapacidad para asegurar una dinámica estable de crecimiento, la frustración de expectativas, las tendencias incontenibles a la agudización de la desigualdad y la multiplicación de la pobreza, la creciente desinte- 


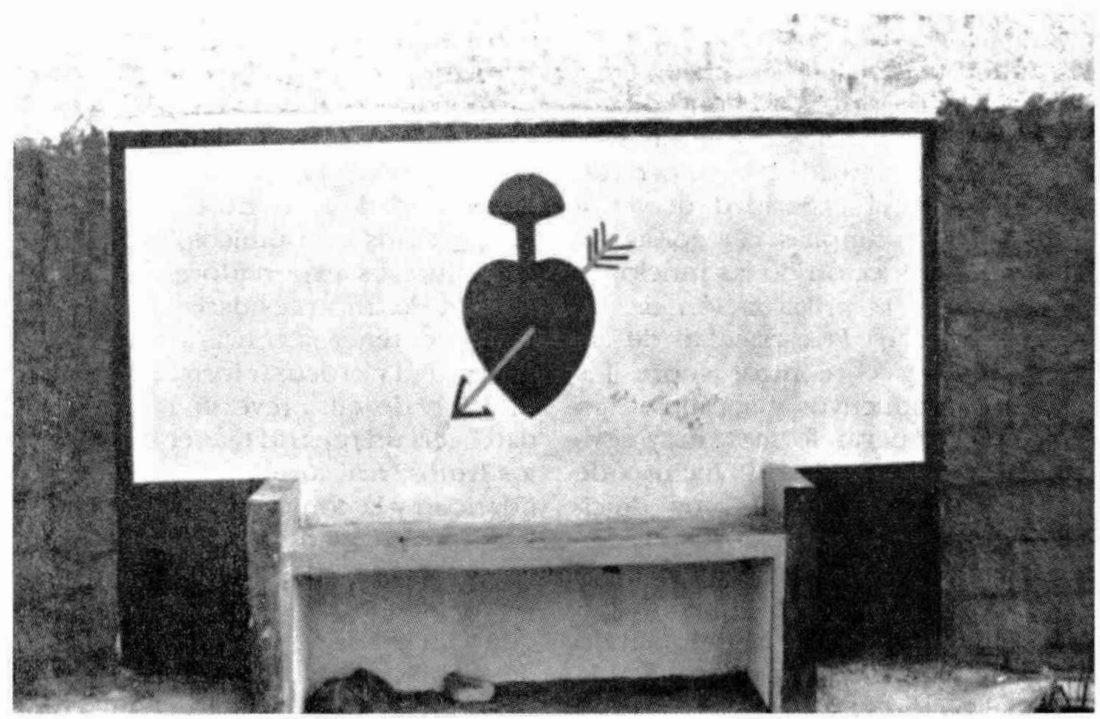

gración social interna y el agotamiento de los primeros beneficios de la apertura externa indiscriminada.

No es pues de sorprender el desenlace de crisis en que acaban por desembocar los proyectos de desarrollo capitalista, en los términos que se han dado en el conjunto del mundo subdesarrollado y particularmente en América Latina, y la reconsideración que, desde distintos ángulos, busca definir nuevas estrategias de desarrollo capaces de superar efectivamente esa crisis. De ahí que, aunque pudiera parecer distante de la realidad inmediata, la idea de un nuevo proyecto social sustitutivo, incluidas las estrategias y políticas consiguientes, surge como exigencia del presente y del futuro de América Latina y adquiere cre- ciente ponderación, tanto en el debate intelectual como en las demandas políticas.

LOS PRINCIPALES CONTENIDOS DE UN PROYECTO ALTERNATIVO

Lo dicho con anterioridad sugiere claramente que una propuesta alternativa, que se proponga imprimir otro sello al desarrollo económico y social, no puede circunscribirse a cuestiones secundarias $o$ accesorias: tiene necesariamente que asumir unos alcances y una naturaleza transformadora que guarde correspondencia con la magnitud de los problemas y desafíos, heredados de la crisis y en muchos casos amplificados por las acciones empren- 
didas bajo la convocatoria neoliberal.

La discusión de su contenido puede comprender un listado de componentes parciales, facilitando así el esclarecimiento de los problemas y la naturaleza y viabilidad de las opciones, pero sin olvidar que ellos tienen que conformar en su conjunto una propuesta global coherente, que dé cuenta debidamente de las interrelaciones estructurales y dinámicas entre las distintas variables económicas, así como de ellas con las sociales y políticas.

Un punto de partida puede referirse a las relaciones y prelaciones entre crecimiento y distribución; para destacar, frente al carácter concentrador del neoliberalismo y su promesa de distribuir después de crecer, la opción de constituir la redistribución en la base de nuevos patrones de crecimiento, lo cual involucra, entre otras cosas, actuar frente a las fuentes mismas de la desigualdad: la propiedad, la distribución funcional del ingreso, la extensión del progreso técnico, el desempleo y la informalidad.

En el mismo ámbito de consideraciones se sitúan los problemas relativos a las potencialidades dinámicas que se identifican en esquemas concentradores $o$ alternativamente en proyectos difusores de los frutos del crecimiento económico, en sus respectivas exigencias de inversión y de productos importados, en sus requerimientos tecnológicos y su capacidad de absorción de mano de obra.

Los cambios en el perfil de la distribución del ingreso, a su vez, se ligan directamente con la estructura productiva. Son bien conocidas las tensiones que se originan cuando se alte- ran en sentido progresivo los parámetros distributivos, que suponen nuevas composiciones de las demandas de consumo, mientras persiste una estructura productiva construida con la referencia de otro patrón distributivo. La superación del "populismo" radica precisamente en la decisión de actuar conjuntamente frente a las relaciones de distribución y a la composición de los flujos productivos, apelando tanto a los factores de flexibilidad de oferta que pudieran existir como a la reasignación de los recursos del proceso inversionista. Es precisamente en esta área de cuestiones donde se pone más abiertamente de manifiesto el tema de los patrones de consumo en su relación con el carácter más o menos igualitario de la sociedad. De otro lado, el neoliberalismo ha venido impulsando una "reconversión productiva" que ha favorecido terminantemente a los bienes "transables", es decir, susceptibles de exportarse, en tanto en esta otra perspectiva se trataría de cambiar el signo de esa reconversión hacia las necesidades básicas internas, de productos y de servicios.

Es insoslayable encarar en ese contexto la naturaleza de la opción preferentemente entre exportaciones y mercado interno. Aunque en abstracto puede sostenerse su conciliación y hasta su complementariedad, en los hechos se presentan diversos factores en abierta oposición (es el caso de la retribución de la fuerza de trabajo, así como la asignación relativa de recursos naturales, productivos y financieros) que acaban por sacrificar un propósito en beneficio del otro. El rasgo típico del neoliberalismo es su 
vocación esencialmente exportadora, con la constatación adicional de que la práctica no sustenta para nada la justificación que se esgrime de que los ingresos derivados de esa exportación pueden financiar con importaciones los déficits internos de necesidades básicas, ya que la mayor parte de esos ingresos queda absorbida por una variedad de factores ajenos a las necesidades internas de consumo. En contraposición, un proyecto alternativo está llamado a jerarquizar mucho más los abastecimientos básicos internos; en todo caso, de ninguna manera es un esquema imposible y nocivo de autarquía, lo cual abre interrogantes respecto de la función que están llamadas a cumplir las exportaciones en este nuevo marco, $y$ las formas de asegurar los ingresos externos indispensables para sostener el funcionamiento y la expansión del sistema. Asunto que muy probablemente tiene también mucho que ver con el tamaño absoluto de la economía nacional correspondiente.

Probablemente la mayor debilidad a mediano y largo plazo de la estrategia neoliberal, sea la de depender vitalmente de la continuidad de un dinamismo exportador, en función de lo cual impulsa la más incondicional apertura externa. En el caso de América Latina, tiende a la integración más plena con las economías desarrolladas, particularmente la de Estados Unidos, en la perspectiva de una "zona continental de libre comercio", abriendo paso a un proceso de fuerte extranjerización de las economías nacionales, subordinando autonomías nacionales e internalizando también las pautas de consumo y formas de vida de aquellas sociedades. Tiene además que luchar en ese empeño contra las consecuencias de las transformaciones tecnológicas contemporáneas, que estrechan cada vez más el horizonte exportador para el mundo subdesarrollado.

Muy probablemente, un proyecto alternativo no puede prescindir de una ampliación de su "espacio externo", lo que obliga a ponderar debidamente las posibilidades de fórmulas de integración regional y subregional en el ámbito del tercer mundo, y particularmente en el de América Latina, no como pasos intermedios hacia zonas mayores de libre comercio con economías desarrolladas, sino como espacio de desarrollo común y como instrumento para negociar mejor con aquéllas los términos de sus relaciones comerciales y financieras. Se requiere pues una ecuación distinta e idónea de las relaciones entre integración social interna, integración económica latinoamericana, relaciones con otras áreas subdesarrolladas y relaciones con las economías más ade. lantadas sin exclusiones entre ellas.

Las formas de absorción y de aplicación del progreso técnico definen otro elemento estratégico importante. El neoliberalismo propicia un esfucrzo intenso de "modernización" entendida de manera singular, que es justificada además como requisito de competitividad externa, lo que lleva a concentrar el progreso técnico en áreas determinadas de la economía y categorías determinadas de productores, por lo general las ya más "tecnificadas" y orientadas preferentemente a 
las exportaciones. Un proyecto alternativo, en cambio, puede requerir que se tienda a privilegiar el avance técnico de los estratos relativamente más re. zagados, de los productores menores y más pobres, vinculados en general al consumo interno de bienes esenciales. Tal política tecnológica tendría dos efectos importantes: de un lado, al atenuar las heterogeneidades estructura. les, contribuye a actuar sobre una de las raíces de la desigualdad; de otro, fortalece la capacidad de producción de bienes y servicios básicos, en mejor correspondencia con una distribución más progresiva del ingreso nacional. En rigor, la "modernización" no es privativa del neoliberalismo; tan "modernizante" es un proyecto que difunde al conjunto de la economía avances técnicos significativos, como otro que concentra las técnicas más avanzadas en áreas determinadas de la economía.

Es claro que cualquier estrategia global de desarrollo involucra, explícita o implícitamente, decisiones en cada uno de los ámbitos señalados, y que esas decisiones deben tener en cuenta además que se trata de elementos que no se pueden combinar de cualquier manera, ya que hay que reconocer en ellos interrelaciones a veces muy estrechas, apremiantes en la coherencia interna de las estrategias que se proponga. Bajo las concepciones neoliberales, por ejemplo, lo más probable es que los términos en que privilegia a las exportaciones al definir su orientación productiva conlleve necesariamente restricciones salariales -por razones de competitividady empeños modernizadores muy concentrados en áreas determinadas, baja capacidad de absorción de fuerza de trabajo y alta exigencia de aprovisionamientos importados, generando así una dinámica incontrarrestable de desigualdad y de persistente desequilibrio externo. Un proyecto alternativo, en cambio, al priorizar las necesidades básicas como eje de la conformación del sistema productivo y de la composición de los flujos de bienes y servicios, probablemente tienda a ampliar más rápidamente el empleo, favorezca mejoramientos de los salarios reales, y requiera menos inversión y menoss abastecimientos importados por unidad de producto.

Las propias políticas económicrs de corto plazo tienen que ajusta'se a opciones de lineamientos estra icgicos de la naturaleza de los que se vienen discutiendo. Tal vez sca precisa. mente en ello donde radiquen las mayores dificultades para la definición de un proyecto alternativo. Porque no se trata sólo de anticipar la aspiración a un conjunto coherente de rasgos económicos y sociales -la "imagenobjetivo" de la sociedad del futuro-, sino de proponer las formas específcas de avanzar hacia ella, sus tiempos, contenidos y secuencias. Queda así abierto el desafio de definir políticas idóneas y coherentes en materias de salarios, precios, subsidios, estímulos; en la de tributación y gasto público; en las políticas antiinflacionarias, las de comercio exterior y relaciones financieras externas. Entretanto, parte de la adhesión al neoliberalismo proviene precisamente de que traduce sus enunciados globales en formas específicas de acción en cada materia particularizada, mientras las propues- 
tas transformadoras alternativas por lo general no alcanzan la misma complementación, dejando la impresión de que no hay opciones a las políticas concretas en práctica, con la constatación adicional de que, muy probablemente, el diseño de las políticas de corto plazo de un proyecto alternativo es mucho más complejo, ya que no puede reproducir el automatismo (del mercado), la globalidad y la "neutralidad" de las políticas neoliberales: necesitan ser mucho más activas y discriminatorias o específicas, en función de las situaciones existentes y de sus propósitos.

Con esta afirmación (o propuesta) no se está haciendo más que reconocer que frente a una realidad esencialmente heterogénea -en sus diferenciaciones económicas y sociales, en los estratos de productividad que configuran el sistema económico, en la gravitación y capacidad de influencia de los distintos agentes económicoslas políticas económicas globales, aparentemente no discriminatorias, terminan por favorecer solamente a los ya más favorecidos. Lo cual justifica una propuesta alternativa que convoca al diseño de políticas diferenciadas, en función de propósitos básicos y en atención a las condiciones específicas de los distintos grupos de consumidores y productores.

En suma, se bosqueja un proyecto alternativo que se inspira en la imagen futura de una sociedad que en tiempo histórico razonable acaba con la pobreza, que asegura a todos los consumos básicos, que sostiene sistemas incluso ejemplares de salud y educación, que resuelve los problemas de una vivienda digna para todos. Se caracterizaría así como una nación integrada socialmente, con rangos moderados de diferenciación en los niveles de vida de distintas etapas y estratos sociales, a cambio de lo cual tendría que ser también una sociedad de sobriedad en el consumo, sin excesos ni "fiebres consumistas", y que asume al mismo tiempo el compromiso de cuidar y defender los recursos, para hoy y para mañana, preservar el medio ambiente y actuar con plena conciencia sobre los fenómenos ecológicos.

\section{LAS PRIORIDADES SECTORIALES Y} LOS AGENTES PRODUCTIVOS

Es claro que un proyecto alternativo de esa naturaleza involucra cambios sustanciales en las prioridades sectoriales, en el papel que se atribuye a las exportaciones y en función de los distintos "agentes productivos" que actúan en la economía y coexisten a veces en el interior de cada sector.

La agricultura, la agroind ustria, y en general la producción de alimentos, las industrias de bienes de consumo difundido, los servicios de educación y salud, los productos farmacéuticos, la actividad editorial, los materiales de construcción y la vivienda, el transporte público, los servicios populares de recreación y cultura, estarían llamados a constituirse en sectores económicos clave de la estructura alternativa; y a partir de ellos, los bie. nes de capital para mantener y ampliar su capacidad productiva, y los productos intermedios necesarios en la elaboración o suministro de los mis- 
mos. En una primera fase, las capacidades productivas de esas ramas actualmente ociosas pueden contribuir a facilitar la armonización entre la vieja estructura productiva, que sólo puede modificarse gradualmente, y las nuevas demandas que con bastante rapidez hace manifiestas la nueva distribución del ingreso. En algún grado, hay también la posibilidad de reconvertir el uso de otras capacidades productivas, desplazándolas de sus producciones actuales a las de otras líneas de consumos básicos, pero en definitiva los desajustes tienen que resolverse mediante cambios en la propia estructura productiva y, en consecuencia, mediante programas de inversión que respondan muy directamente a esas nuevas prioridades.
Por su parte, en ese contexto cambia también la significación que se atribuye a las exportaciones: ya no se trataría tanto de promoverlas a toda costa para prolongar las estrategias en práctica (es decir, cuánto es el máximo que se podría exportar), sino más bien qué capacidad para importar resultaría indispensable para sustentar los nuevos términos de funcionamiento y crecimiento del sistema económico en esa estrategia alternativa.

En verdad, la "reconversión" que involucra esta propuesta no se refiere sólo a las ponderaciones "sectoriales". En un sentido más amplio, vendría a representar un esfuerzo decidido para revalorar la función directamente productiva frente al enorme espacio que en el neoliberalismo han ganado las

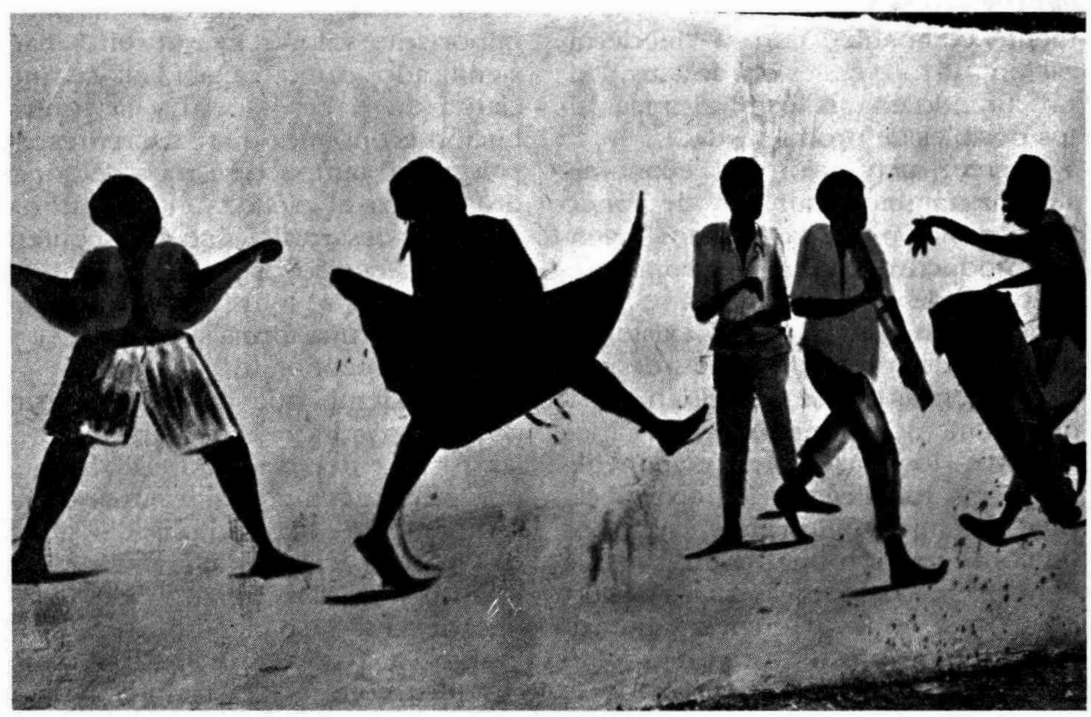

UN PROYECTO SOCIAL ALTERNATIVO 
actividades financieras; es decir, fortalecer la base de producción material y la capacidad de suministro de servicios básicos en lugar de que se sigan ampliando las actividades de naturaleza esencialmente especulativa.

Desde otro ángulo, una propuesta de este signo no supone en modo alguno sacrificio de "eficiencia económica" o despreocupación por ella, en ninguno de los dos sentidos en que puede definirse' esa eficiencia. Primero, porque representaría un esquema de prioridades que no puede valuarse por las reglas directas del mercado, por la capacidad para generar ganancias de los dueños del capital, sino por un criterio fundamental de "eficiencia social", del grado en que cumple una función útil para los destinatarios naturales del esfuerzo económico el conjunto de la población. Y segundo, porque es perfectamente compatible con la "modernización" de toda esa esfera de actividad, procurando en ella los niveles más altos posibles de productividad.

Tal reestructuración de la economía supone también cambios de fondo en la posición de los distintos "agentes productivos" y en las propias relaciones de propiedad. En ella se concibe, en efecto, una coexistencia mucho más amplia de formas de propiedad, en las que se reducirían considerablemente -al menos en términos relativos- los espacios que en el neoliberalismo han llegado a ocupar el capital extranjero y los grandes grupos de concentración interna en favor de empresas estatales en áreas muy seleccionadas y de las pequeñas y medianas empresas privadas, en un proceso de verdadera democratización de la propiedad. Por su parte, la dimensión que ha llegado a tener la "economía informal" abre un ancho campo para definir con criterios creativos e innovadores nuevas formas de propiedad y de organización económica: no se trata, como en la estrategia neoliberal, de la permanencia y ampliación de la economía informal como válvula de escape a los problemas de un sector formal moderno y para hacerse cargo de los empleos que éste no genera, sino de abrir a ese enorme sector perspectivas de tecnificación y desarrollo, apoyado en la promoción de cooperativas y otras de "modernización".

Algo similar ocurre con la variedad de "organizacionnes económicas populares" que han surgido en el curso de la crisis como instrumento de sobrevivencia de los estractos sociales más empobrecidos. Es muy importante valorar lo que ellas han significado como capacidad de iniciativa de la base social y la contribución económica que han representado, pero tampoco se trata de constituirlas en el eje de una estrategia nueva de desarrollo, sino de asegurarles todos los apoyos para que, cuando corresponda, se transformen cualitativamente en una forma superior de organización económica.

Es evidente que a nada de esto podrian conducir, espontáneamente, las fuerzas del mercado. De hecho, una estrategia alternativa supone necesariamente una responsabilidad y una participación mucho mayor del Estado, lejos sin embargo de identificarlo con una planificación "totalizante" y a la postre ineficaz, sino con una concepción también nueva 
del Estado, coherente tanto con esa estrategia económica como con las demandas y aspiraciones de democracia, tal vez uno de los desafios mayores que queda abierto a un proyecto social alternativo del diseño y puesta en práctica de una concepción nueva de relación e integración de elementos de planificación y espacios de mercado; en lo que muy probablemente la clave terminará por radicar es en una concepción muy amplia de la participación social, de la participación popular activa en todas las instancias de dirección y gestión de la economía.

\section{LA VIABILIDAD DE UN PROYECTO ALTERNATIVO}

Una imagen de sociedad como la insinuada, es perfectamente alcanzable en los marcos de una estrategia alternativa de desarrollo, en un proceso difícil pero técnicamente viable de cambios profundos respecto de las estrategias y políticas actualmente predominantes. Los mayores obstáculos, más que económicos, son esencialmente políti$\cos$, sin que ello implique desconocer la dimensión y trascendencia de los primeros.

Las potencialidades son, en efecto, al menos tan grandes como las dificultades y los desafios. Desde luego, porque un rasgo específico del subdesarrollo capitalista del presente es el desperdicio de toda suerte de recursos y posibilidades, desde recursos naturales hasta recursos humanos, pasando por los recursos de capital ya acumulados. La mala utilización de ellos arranca de su subordinación a determinadas pautas de relaciones sociales, a la lógica del mercado imperante, de modo que un proyecto alternativo que rompa esas limitaciones institucionales y sociales puede movilizar energías y potencialidades que ahora están esterilizadas por aquella subordinación. La infraestructura ya construida, las ca. pacidades productivas disponibles, la dimensión y variedad de los recursos naturales, la capacitación de la fuerza de trabajo, permitirían con otra conducción del sistema económico, generar una corriente significativamente mayor de bienes y servicios, y en muchos casos los déficit en la condición de vida no provienen tanto de la imposibilidad de ingresos para acceder a ellos, de amplias capas de la población. No habría tampoco razón objetiva para negar la posibilidad de que bajo otra dirección de la economía se pudieran generar unas dinámicas positivas de crecimiento en beneficio directo de la mayoría de la sociedad.

El problema es, como ya se ha dicho, esencialmente político. Hoy día, las clases dominantes imponen en todas sus manifestaciones la dirección que conviene a sus intereses; pero no es la única dirección posible: en función de los intereses nacionales y populares, es perfectamente posible revertir el signo de esa estrategia global y de cada uno de sus componentes parciales.

Por su parte, las condiciones de viabilidad política son por cierto muy complejas. Como ocurre con toda propuesta transformadora, ella no podría ser asumida y conducida por los mismos intereses actualmente dominantes. Supone, por tanto, la capacidad para reunir una fuerza social a la vez muy amplia y con objetivos inequívocos de cambio -marcando así una di- 
ferencia fundamental con las fórmulas actuales de "concertación"- que gane el poder político necesario, requerimiento que encuentra por supuesto no sólo grandes escollos reales, sino que tiene que encarar también las consecuencias de influencias ideológicas extensamente difundidas, que llevan a que variados segmentos de la sociedad asuman conductas políticas contradictorias con sus intereses objetivos, reduciendo los ámbitos de lo que debería ser una amplísima mayoría social de respaldo a esos cambios. Ademas de los aspectos técnico-políticos hay tal vez, de manera general, otros tres órdenes de consideraciones respecto de la viabilidad propiamente política de un proyecto social alternativo de sello popular y nacional. Teniendo en cuenta además que la viabilidad política de cualquier proyecto social no es un dato que esté dado de antemano: hay que entenderla como un proceso de construcción progresiva de viabilidad, de acumulación constante de fuerzas y respaldos que se va ganando en el curso mismo de la lucha por el nuevo proyecto social.

En primer lugar, es un hecho que el carácter concentrador y excluyente del patrón de desarrollo capitalista prevaleciente ha acabado por castigar y perjudicar a un espectro extraordinariamente amplio de intereses sociales. Ello quiere decir que quienes, en razón de sus intereses objetivos, deberían estar en favor de cambios profundos, constituyen una mayoría abrumadora de la sociedad. El desafio, en ese sentido, es el de neutralizar los efectos de la difusión ideológica que han inculcado otras disposiciones subjetivas, que inducen a muchos de ellos a solidarizarse con intereses que no son los suyos. Incluso grupos sociales que a corto plazo probablemente no tendrían mucho que ganar de un proyecto transformador en su acceso a bienes materiales, puede legítimamente movilizarse en su favor en función de otros valores y aspiraciones; por ejemplo, en la seguridad de su vida diaria, expuestos como están en la sociedad actual a la violencia cotidiana que con frecuencia les impide disfrutar de las ganancias materiales que han obtenido.

En segundo lugar, es preciso forjar condiciones de solidaridad internacional, de relación entre las fuerzas progresistas de los diversos países, para que defiendan y apoyen el ejercicio pleno del derecho a la autonomía nacional, el respeto a la voluntad de cada pueblo para decidir sobre el signo que quiera imprimir a su desarrollo económico, social y político, tantas veces atropellado en la expe. riencia histórica.

Finalmente, está la fuerza del simple hecho de que la puesta en práctica de un proyecto social alternativo, inspirado en los intereses nacionales y populares, es en este presente una necesidad objetiva insoslayable, ante los daños actuales y potenciales de la vigencia de las estrategias neoliberales. No obstante el clima preponderante de desesperanza, de conservadurismo, de apelación constante a un supuesto "realismo" que busca desautorizar por "utópico" todo lo que involucra cambios significativos, lo cierto es que, hoy día, tal vez no haya nada más utópico que suponer o procurar que las cosas puedan seguir como están o como han venido ocurriendo. 